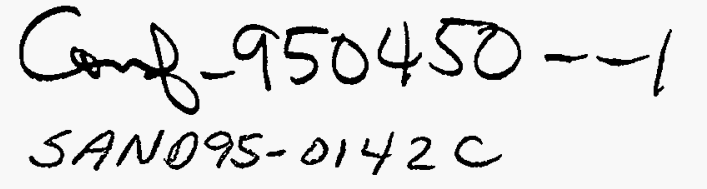

\title{
GroundWater Flow VeloctTy MEASUREMENTS in a SinKHOLe at THE Weeks Island Strategic Petroleum Reserve Facility, Louisiana
}

\author{
Sanford Ballard \\ Sandia National Laboratories \\ Albuquerque, NM \\ (505) 844-6293 \\ James Gibson \\ SIE, Inc., Division of Computalog USA \\ Fort Worth, TX \\ (817) 249-7200
}

\begin{abstract}
In 1992, a sinkhole was discovered above a Strategic Petroleum Reserve storage facility at Weeks Island, Louisiana. The oil is stored in an old salt mine located within a salt dome. In order to assess the hydrologic significance of the sinkhole, an In Situ Permeable Flow Sensor was deployed within a sandfilled conduit in the salt dome directly beneath the sinkhole. The flow sensor is a recently developed instrument which uses a thermal perturbation technique to measure the magnitude and direction of the full 3-dimensional groundwater flow velocity vector in saturated, permeable materials. The flow sensor measured substantial groundwater flow directed vertically downward into the salt dome. The data obtained with the flow sensor provided critical evidence which was instrumental in assessing the significance of the sinkhole in terms of the integrity of the oil storage facility.
\end{abstract}

\section{INTRODUCTION}

The U. S. Strategic Petroleum Reserve operates an oil storage facility at Weeks Island, Louisiana, in which approximately 70 million barrels of crude oil are being stored in an old abandoned salt mine contained within a salt dome. In May of 1992, a sinkhole was discovered in the sandy sediments overlying the salt dome, directly above one edge of the subsurface storage facility. There are two conceptual models of the origin of the sinkhole. The first involves a fissure or topographic canyon in the top of the salt dome which is carrying groundwater horizontally off the top of the dome. The second model, illustrated in Figure 1, involves a thin crack in the salt which extends from the top of the salt dome down to the storage facility. As watei flows down the crack into the storage facility, salt is dissolved from the walls of the crack until the water becomes saturated, creating a downwardly propagating void in the salt which is filled with sand derived from the unconsolidated sandy sediments which overly the salt dome. As sediments continue to flow into the propagating void, a sinkhole ultimately forms at the ground surface. To differentiate between these two models and to characterize the relationship between the sinkhole at the surface, the groundwater in the sediments above the salt dome

This work was supported by the United Stapes Department of Energy under Conir_et CE-ACnA.94ALR5nno.



Figure 1 - Generalized cross section through the sinkhole site.

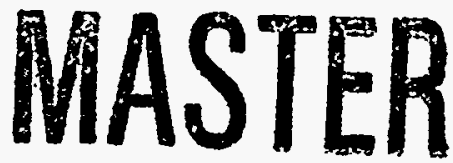




\section{DISCLAIMER}

This report was prepared as an account of work sponsored by an agency of the United States Government. Neither the United States Government nor any agency thereof, nor any of their employees, makes any warranty, express or implied, or assumes any legal liability or responsibility for the accuracy, completeness, or usefulness of any information, apparatus, product, or process disclosed, or represents that its use would not infringe privately owned rights. Reference herein to any specific commercial product, process, or service by trade name, trademark, manufacturer, or otherwise does not necessarily constitute or imply its endorsement, recommendation, or favoring by the United States Government or any agency thereof. The views and opinions of authors expressed herein do not necessarily state or reflect those of the United States Government or any agency thereof. 


\section{DISCLAIMER}

Portions of this document may be illegible in electronic image products. Images are produced from the best available original document. 
and the oil storage facility, a comprehensive suite of investigations was initiated (Bauer, 1994). As part of this effort, several boreholes were drilled in the vicinity of the sinkhole, including a slant hole which penetrated a sand filled conduit deep within the salt. An In Situ Permeable Flow Sensor was emplaced into this borehole to measure the direction and magnitude of the groundwater flow velocity within the sand-filled conduit. Significant horizontal groundwater flow would suggest that water is flowing off the top of the salt dome while primarily vertical flow would support the existence of a groundwater leak into the oil storage facility.

In Situ Permeable Flow Sensors are new instruments which use a thermal perturbation technique to directly measure the magnitude and direction of the full three dimensional groundwater flow velocity vector characteristic of an approximately $1 \mathrm{~m}^{3}$ volume of the subsurface (Ballard et al., 1994). The basic principle of operation of this technology is to bury a long thin heated cylinder with an array of surface mounted temperature sensors in direct contact with the saturated, permeable formation at the point where the flow velocity measurement is to be made. The heat emanating from the probe warms the ground and the water surrounding the instrument. In the absence of any flow past the device, the temperature distribution on the surface of the.cylinder is independent of azimuthal position on the probe and symmetric about the vertical midpoint on the probe. The ends of the probe are cooler than the vertical midpoint because heat transfer away from the ends of a finite length heated cylinder is more efficient than from the midsection. If there is flow past the device then the heat emanating from the surface of the probe is advected around the device by the flowing water with the result that the probe is somewhat cooler overall than when there is no flow and the upstream side of the probe is cooler than the downstream side. Figures $2 a$ and $2 b$ illustrate the theoretical temperature distributions expected in horizontal and vertical flow fields, respectively. The direction and magnitude of the full three dimensional groundwater flow velocity vector can be determined by calculating the flow velocity which results in the best fit between the observed temperature distribution on the surface of the probe and the theoretical temperature
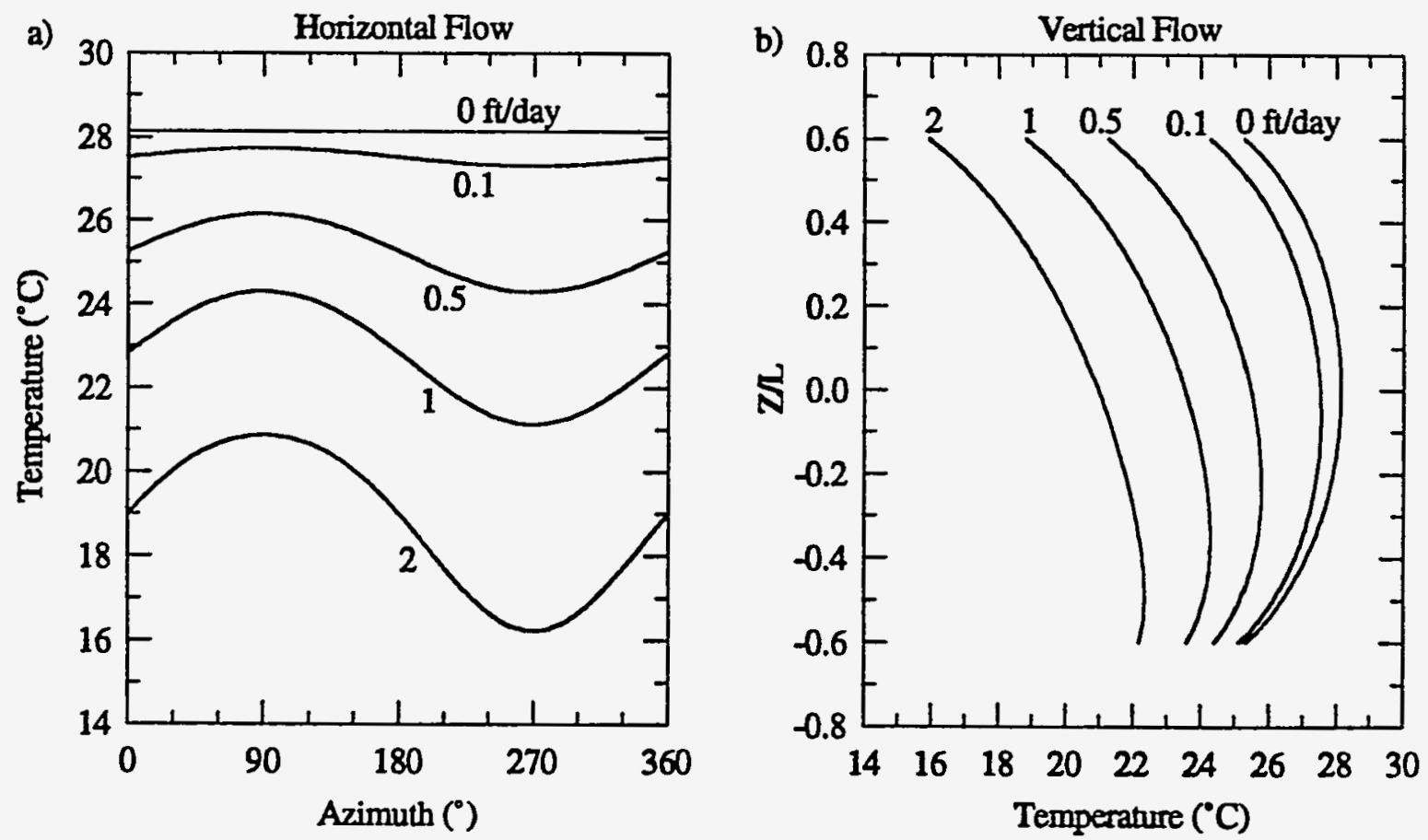

Figure 2 - Theoretical surface temperature distributions expected on probes buried in a) purely horizontal and b) purely vertical flow fields. In a) the flow is oriented toward $90^{\circ}$ from the reference direction. 
distribution calculated according to a formula derived by Romero (in press). For a complete description of the technology see Ballard et al. (1994).

An In Situ Permeable Flow Sensor was emplaced in borehole BH7A (Figure 1) on July 3, 1994, which was only a few days after the hole was drilled. BH7A is a slant hole which intersected the top of the salt at a depth of approximately 190 feet below the surface. The hole penetrated through approximately 60 vertical feet of salt at an angle of approximately $30^{\circ}$ from the vertical before encountering sand again at a true vertical depth of approximately 250 feet. To emplace the probe, HQ casing was lowered down the hole until sand which had flowed a few feet up into the salt was encountered. Brine was pumped down the casing and the casing was advanced 13 feet past the salt/sand interface in this fashion. The flow meter was lowered down the inside of the casing and flushed out past the end of the casing with brine. The casing was removed and the sand collapsed around the probe, leaving it buried in the formation. The probe was connected to a data acquisition system at the surface via electrical cables housed in 1 inch diameter PVC conduit. This conduit was marked in such a way that the horizontal (azimuthal) orientation of the probe was known after emplacement. The thermal disturbance introduced into the subsurface by pumping brine into the ground was allowed to decay overnight and the heater on the probe was activated at a power level of 80 watts on July 4th. The probe began providing useful flow information on July 5 th. Data was collected from the probe on a continuous basis until July 21 st when operations ceased.

\section{RESULTS}

Figure 3 shows the temperatures measured by the 30 temperature sensors on the surface of the probe as a function of time. Before activation of the heater, the temperature of the subsurface was approximately $23^{\circ} \mathrm{C}$. When the heater was activated on July 4 th, the temperature of the surface of the probe increased dramatically with the temperature at some locations increasing much more than at other locations. After July 5 th, the temperature of the probe continued to increase even though the power output of the heater remained constant. In addition, the spread of temperatures decreased with time. Figure 4 illustrates the vertical temperature distribution on the surface of the probe as a function of time. Each curve in Figure 4 shows the temperature distribution on a different day. The most important feature to note is that throughout the time that measurements were made, the top of the probe was relatively cool and the bottom of the probe relatively warm, indicating that the heat emanating from the probe was being advected downward by groundwater flowing vertically downward past the probe. A small component of flow oriented in a direction perpendicular to the long axis of the probe was also observed but is consistent with the fact that probe was not oriented vertically in the ground. As far as the direction of the flow velocity is

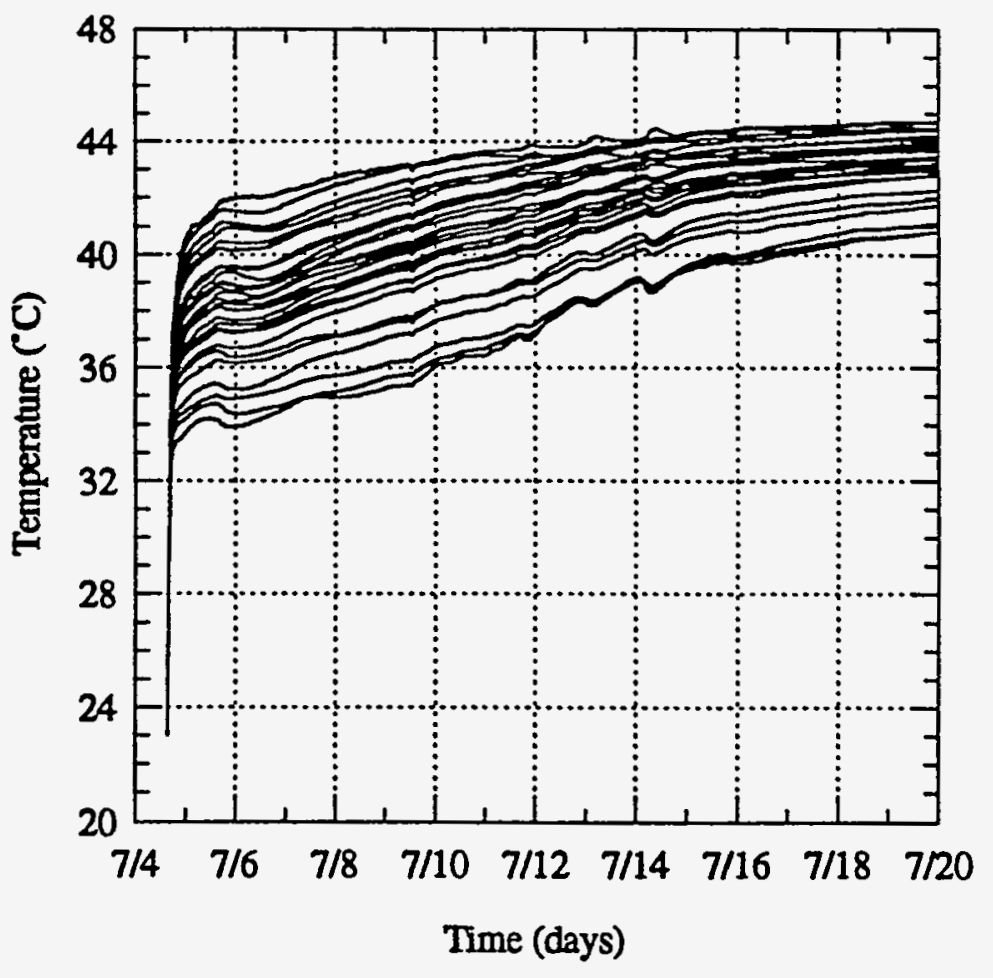

Figure 3 - Temperature of the 30 temperature sensors on the surface of the probe as a function of time. 
concerned, the temperature distribution is unambiguous: large, downwardly directed flow with insignificant horizontal flow was observed. The fact that the probe increased in temperature and the vertical temperature distribution became more symmetric with time indicates that the downward flow velocity decreased in magnitude significantly during the course of the measurement period.

Figure 5 illustrates the magnitude of the downwardly directed flow velocity as a function of time. The flow started off at about 4 feet/day. It decreased rapidly at first but appeared to be levelling off at about 0.5 to $1.0 \mathrm{ft} / \mathrm{day}$ by the end of the data collection period. The procedure for calculating the flow velocity described in Ballard et al. (1994) relies primarily on the relative temperature distribution on the surface of the probe, not on the absolute temperature of the probe. The technique described in Ballard et al. (1994) is valid for flow velocities in the range of about 0.01 to 1.5 $\mathrm{ft} /$ day. Above about $1.5 \mathrm{ft} /$ day, the inversion scheme is not particularly robust. The velocity magnitudes reported in Figure 5 are calculated primarily from the absolute temperature of the probe. The two techniques agree well for velocity magnitudes less than $1.5 \mathrm{ft} /$ day.

A plausible explanation for the observed decrease the magnitude of the downward flow is that several thousand gallons of saturated brine were injected into the hole during the drilling of the hole and the installation of the flow sensor. Assuming that the original water in the sand-filled conduit was only partially saturated with salt, the injected brine would have had a higher density than the original water and would have flowed downward, past the probe, in response to the contrast in density. The data in Figure 5 indicate that this transient

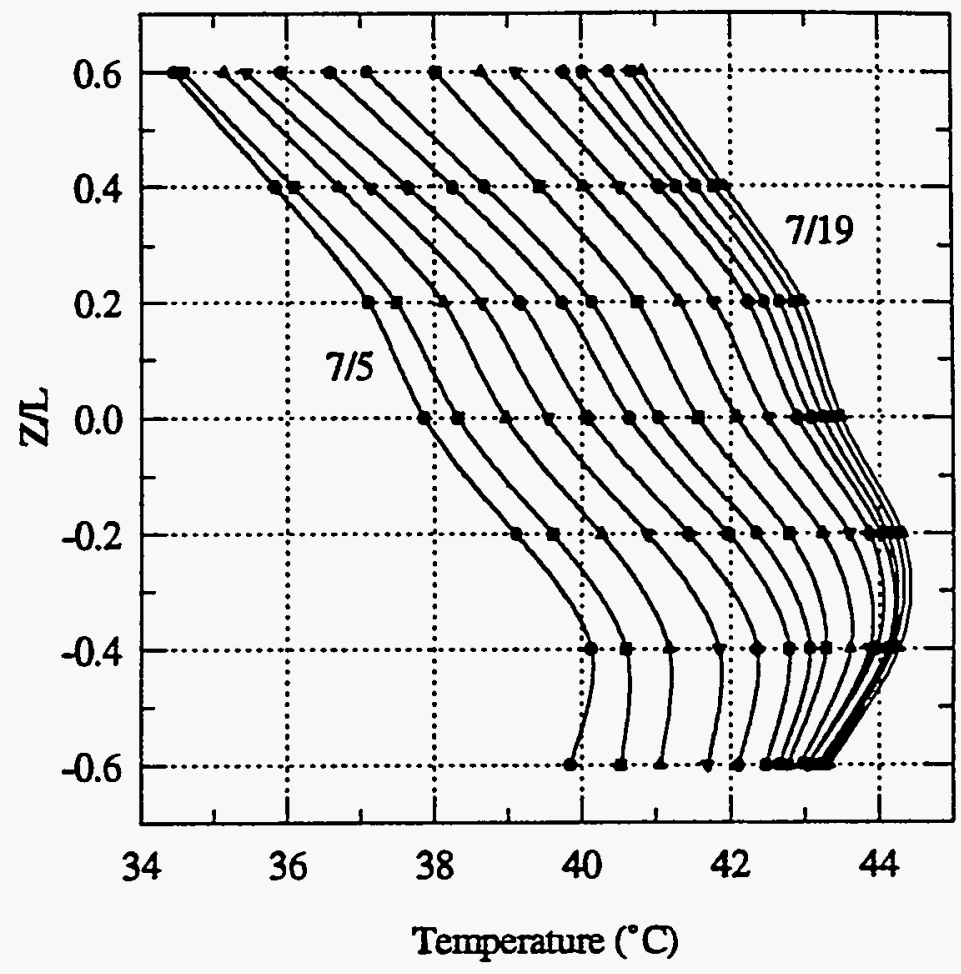

Figure 4 - Vertical temperature distribution on the surface of the probe as a function of time. The symbols represent the measured values at seven of the temperature measurement locations while the curves are cubic spline fits to the data. On the vertical axis, 0 represents the vertical midpoint of the probe while -1 and 1 would represent the bottom and top of the probe, respectively.

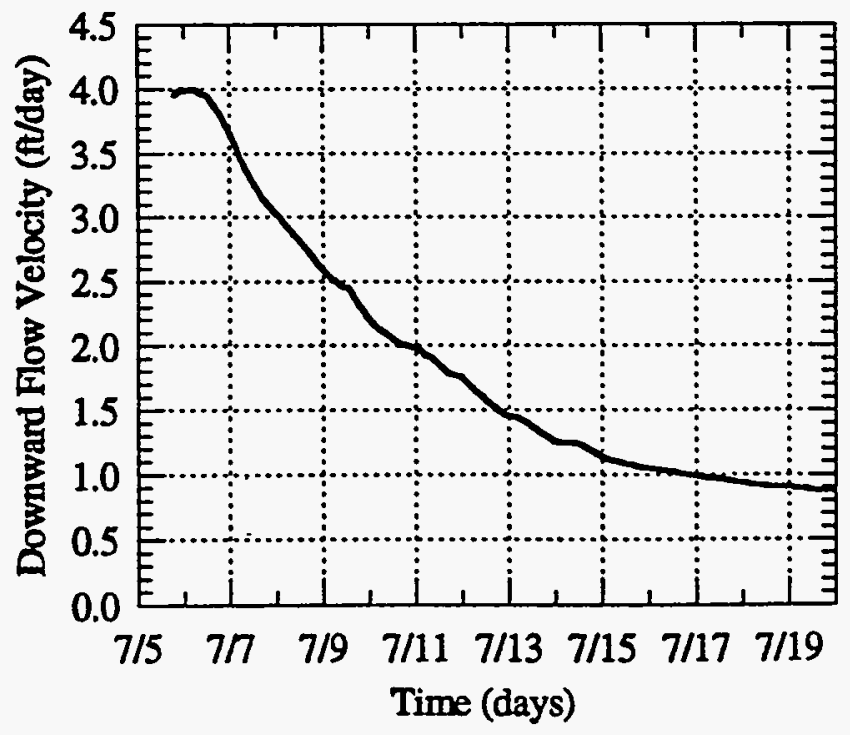

Figure 5 - Magnitude of the downwardly directed vertical flow velocity as a function of time. 
component of the flow had decayed away after approximately two weeks and the final measurements, indicating a downward flow of about $0.9 \mathrm{ft} /$ day, represent the natural downward flow in the conduit below the sinkhole.

Another interesting observation is that the flow sensor was being carried downhole by sand flowing downward in the conduit. As previously mentioned, the probe was connected to the surface by 1 inch diameter PVC pipe. Figure 6 shows the downward displacement of the top of this pipe as a function of time. The data indicate that the pipe was being carried into the hole at a rate of $1 \mathrm{inch} /$ day. The sediment movement must have been in a predominantly downward direction since any significant horizontal movement would have broken the electrical connection between the flow sensor and the data acquisition system at the surface. These data are in agreement with the rate of growth of the sinkhole observed at the surface.

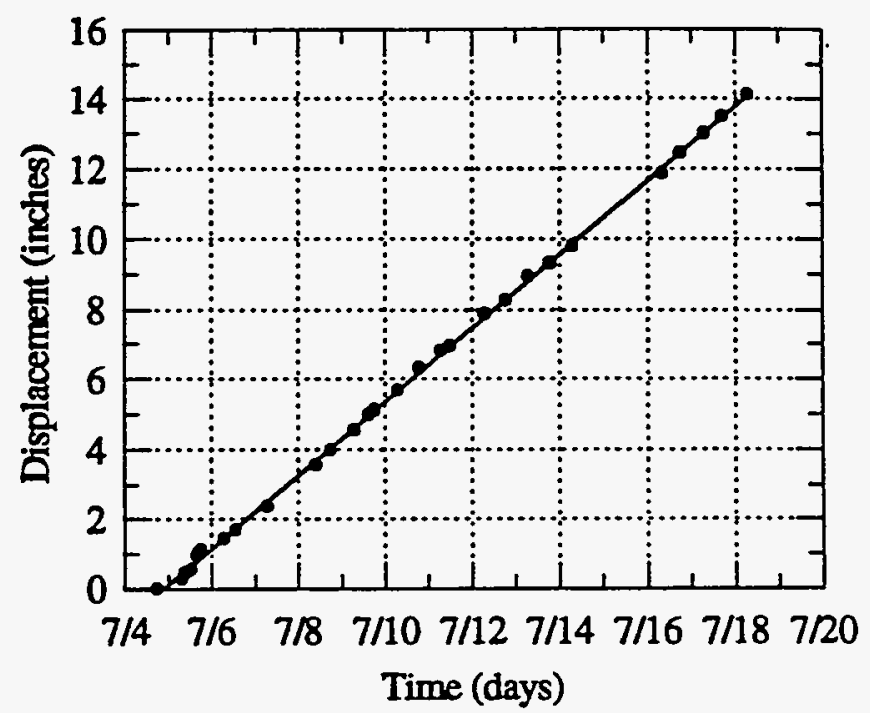

Figure 6 - Tool displacement downhole. Symbols represent measured values and the line is a linear least squares fit to the data. The tool was moving downhole at a rate of 1.05 inches/day.

\section{CONCLUSION}

The downward groundwater flow observed in the sand-filled conduit beneath the sinkhole strongly suggests that groundwater is leaking into the oil repository. The alternative explanation, that the sinkhole is connected to a channel in the top of salt where water is flowing off the dome would seem to require horizontal flow; only vertical flow was observed. The flow sensor proved to be a very valuable tool for characterizing the hydrologic regime beneath the sinkhole.

\section{REFERENCES}

Ballard, S., G. T. Barker and R. L. Nichols, 1994, The In Situ Permeable Flow Sensor: A device for measuring groundwater flow velocity, Sandia report SAND93-2765.

Bauer, S. J., 1994, Update of assessment of geotechnical risks, Strategic Petroleum Reserve, Weeks Island Site, Sandia report SAND942969.

Romero, L. A., 1994, Forced convection past a slender body in a saturated porous medium, accepted by Soc. of Ind. and App. Math., Journal of Applied Mathematics. 